\title{
The Hugh Sinclair Unit of Human Nutrition - 20 years of research 1995-2015
}

Article

Accepted Version

Lovegrove, J. A., Commane, D. M., Jackson, K. G., Karani, V., Kennedy, O. B., Kuhnle, G. G., Spencer, J. P. E., Wagstaff, C. and Yaqoob, P. (2015) The Hugh Sinclair Unit of Human Nutrition - 20 years of research 1995-2015. Nutrition Bulletin, 40 (4). pp. 303-314. ISSN 1467-3010 doi:

https://doi.org/10.1111/nbu.12176 Available at https://centaur.reading.ac.uk/55079/

It is advisable to refer to the publisher's version if you intend to cite from the work. See Guidance on citing.

To link to this article DOI: http://dx.doi.org/10.1111/nbu.12176

Publisher: Wiley

All outputs in CentAUR are protected by Intellectual Property Rights law, including copyright law. Copyright and IPR is retained by the creators or other copyright holders. Terms and conditions for use of this material are defined in the End User Agreement.

www.reading.ac.uk/centaur 
Central Archive at the University of Reading

Reading's research outputs online 


\section{News and Views}

The Hugh Sinclair Unit of Human Nutrition - 20 years of research 1995-2015.

JA Lovegrove, DM Commane, KG Jackson, GG Kuhnle, JPE Spencer, C Wagstaff, P Yaqoob.

Hugh Sinclair Unit of Human Nutrition, Department of Food and Nutritional Sciences, University of Reading, Whiteknights, Reading, UK.

Correspondence: Professor Julie A. Lovegrove, Professor of Human Nutrition. Head of the Hugh Sinclair Unit of Human Nutrition and Deputy Director of the Institute for Cardiovascular and Metabolic Research (ICMR), Hugh Sinclair Unit of Human Nutrition, Department of Food and Nutritional Sciences, University of Reading, Whiteknights, PO Box 266, Reading RG6 6AP, UK.

Phone Number: +44 (0)118 3786418

Fax Number: +44 (0)1189310080

Email: j.a.lovegrove@reading.ac.uk 


\section{Abstract}

The Hugh Sinclair Unit of Human Nutrition (HSUHU) at the University of Reading was founded in October 1995 with the appointment of Christine Williams OBE as the first Hugh Sinclair Chair in Human Nutrition. This was made possible by the competitively won funds from the estate and legacy of the late Professor Hugh Macdonald Sinclair (1910-1990). The vision for the newly established HSUHN was to 'strengthen the evidence-base for dietary recommendations for prevention of degenerative chronic diseases'. This has remained the research focus of the HSUHN under the leadership of Professors Christine Williams (1995-2005), lan Rowland (2006-2013) and Julie Lovegrove (2014-present). Our mission is to improve population health and evaluate mechanisms of action for the effects of dietary components on health, which reflects Hugh Sinclair's life ambition within nutritional science. Over the past 20 years, the HSUHN has developed an international reputation within the nutrition science community and, in recognition of the $20^{\text {th }}$ Anniversary, this paper highlights Hugh Sinclair's contributions to nutritional science and key research achievements by members of the Unit.

Key words: Hugh Sinclair, University of Reading, nutrition, public health, chronic disease prevention, sustainability. 


\section{Hugh Sinclair's contribution to nutritional sciences}

A passionate advocate of nutrition and the importance of diet on health promotion and disease prevention, Hugh Sinclair (Figure 1) was one of the first academics to hold a title in the discipline of nutrition in the UK (Reader in Nutrition 1951, Magdalen College Oxford). At this time, nutrition was viewed by many to be a subject that was unworthy of scientific research (Ewin \& Horrobin 2001), a view that was not held by Hugh Sinclair, who dedicated his life to furthering the study of the discipline. After Hugh Sinclair's death in 1990, a friend and colleague Dr David Horrobin said, 'He may prove to be one of those people whose long-term influence is far greater than ever seemed likely while he was alive'. This now seems prophetic given the wide acceptance of his theories on the impact of long chain (LC) n-3 polyunsaturated fatty acids (PUFA) on cardiovascular disease (CVD), that have helped to inform UK dietary recommendations for the intake of oily fish. The legacy of his foundation also established nutrition as a key research area at the University of Reading through the creation of the Hugh Sinclair Unit of Human Nutrition (HSUHN).

Hugh Sinclair studied for a BSc in Physiology at Oriel College Oxford and then obtained his Doctor of Medicine (DM) from Oxford in 1939, after receiving his Licentiate in Medicine and Surgery from the Society of Apothecaries, Bachelor of Medicine and Bachelor of Chemistry from University College Hospital. During this period he was elected as University Demonstrator and Lecturer in Biochemistry and as a Fellow of Magdalen College, Oxford. Aged 31, the Ministry of Health invited Hugh Sinclair to set up the Oxford Nutrition Survey (ONS), latterly known as the Laboratory of Human Nutrition, which he directed from 1942 to 1955 . The purpose of the ONS was to establish the health of the British population and ensure nutritional adequacy was maintained during the Second World War. Detailed surveys were conducted by a team of 24 staff in a variety of civilian groups in the UK, including students and pregnant women, to ensure that government food rations were sufficient. The tests conducted by ONS, included: anthropometric measurements, clinical assessments (see Figure 2), blood tests (haemoglobin, clotting time, red and white cell counts, vitamin C, vitamin $B_{2}$ ) and urine nitrogen measurements. In addition to his work in the UK, Hugh Sinclair also visited British-occupied areas of Germany and The Netherlands post- war to assess the impact of the widespread famine on health and nutritional status in populations on the brink of starvation (Figure 3). In recognition of this work, Hugh Sinclair was awarded the prestigious US Medal of Freedom with Silver Palm in 1946 (Lloyd 2004).

From 1951 to 1958 Hugh Sinclair was appointed Reader in Nutrition at Magdalen College Oxford. It was during this period that he developed his lifelong interest in the benefits of LC $n-3$ PUFA and chronic disease prevention. The dietary recommendation of consuming two portions of fish a week, 
at least one of which is oily, to provide a daily intake of $0.45 \mathrm{~g}$ of eicosapentaenoic acid (EPA) and docosahexaenoic acid (DHA) (SACN 2003) is now standard dietary advice for the primary prevention of CVD. However, in 1956 when Hugh Sinclair proposed, in his letter to the Lancet (Sinclair 1956) that the observed increase in 'diseases of civilisation' could be attributed to a chronic deficiency of essential fatty acids, specifically LC n-3 PUFA, it was met with considerable scepticism. This controversial letter, resulted in the longest correspondence seen in the medical journal and was considered by many senior scholars to be too speculative and lacking in evidence. In this publication he wrote: 'My purpose in sending you these speculations, which are supported by experimental evidence, is to try to help and prevent the devastating and usually increasing mortality from atherosclerosis' (Sinclair 1956). Hugh Sinclair was a true pioneer, with a firm belief in the role of LC n-3 PUFA in human health, but seldom published his findings. This left his fellow scientists unconvinced of the importance of the link between LC n-3 PUFA and CVD until much later in his life.

From 1958, Hugh Sinclair dedicated much of his time to raising funds to establish the International Nutrition Foundation, researching the role of fish oils in atherosclerosis and heart disease, and supervising students as a Fellow of Magdalen College. It was during this time that he conducted his renowned 'Eskimo experiment' after developing an interest in the Inuit diet whilst studying snow blindness in Canada during World War II. He observed that, despite a high intake of dietary fat, the Inuit population had a very low prevalence of heart disease. Sinclair believed this was due to the effects of LC n-3 PUFA (so called 'essential fatty acids') found in fish, whale and seal meat consumed in high quantities, on reduced platelet aggregation and hence the prevalence of coronary thrombosis, a view also held by Bang and Dyerberg (Bang, Dyerberg and Sinclair 1980). Following a trip to Greenland to study the Inuit's diet, he made plans to test this hypothesis in the UK by investigating the effect of an Inuit diet, high in LC n-3 PUFA-rich foods, on blood clotting time. He struggled to obtain funding for the study, which research councils felt was 'unethical' and 'based on limited evidence', and in 1979 (at the age of 69 years) he joined the ' $n=1$ club' choosing to experiment on himself, believing this was the only way to further human nutrition. For 100 days he consumed only seal meat, fish and water, periodically cutting his arm under controlled conditions to measure the time it took for his blood to clot (Figure 4). The result of this extreme diet was impressive, with an increase in his bleeding time from three to fifty seven minutes, which reportedly caused 'Sinclair's boots to fill with blood when he pruned his roses' (McLean 2002) and the other diners in Magdalen College to complain venomously about the smell of seal meat. Unfortunately, although this study is renowned in the nutrition field and among fellow scientists, the research was never published and it wasn't until much later that the significance of this work was recognised. 
In the latter part of his life, Hugh Sinclair was in high demand as public speaker and lecturer. His early speculation about LC n-3 PUFA and 'diseases of civilisation' had become more widely accepted by the 1970s, and Hugh Sinclair began to receive recognition from fellow scholars and academics for his pioneering work. During this period, until the year he died, Hugh Sinclair was appointed as a visiting Professor of Nutrition at the University of Reading inspiring many students and staff alike (Fallaize and Lovegrove 2013).

\section{The beginnings of the Hugh Sinclair Unit of Human Nutrition}

After Hugh Sinclair's death in 1990, applications for funds from his estate and personal effects, left to the International Nutrition Foundation for nutrition research, were received from the University of Oxford, Oxford Brookes University and the University of Reading. Dr Ann Walker and the late Professors Harry Nursten and Ray Dils were instrumental in securing the endowment for the University of Reading. In 1995 the Department of Food Science and Technology (now the Department of Food and Nutritional Sciences) was endowed with Hugh Sinclair's estate to establish the HSUHN. In addition, Hugh Sinclair's personal effects and research data were also donated to the University. In 2008 a qualified archivist, Hayley Whiting, was appointed to list and catalogue his extensive collection of artefacts, including a vast quantity of data from the ONS. Hugh Sinclair was an obsessive record keeper, rarely disposing of anything and over 1100 office storage boxes of documents and personal effects were filed for archiving. This mammoth task was completed in May 2013, and Hugh Sinclair's archives are now available in the University of Reading's Museum of English Rural Life (MERL) for public consultation. Hayley spoke fondly of this impressive 5-year challenge. Her favourite items included a large plastic mackerel, given to Hugh Sinclair by the students from the University of Reading, and photographs of Hugh Sinclair on his numerous trips abroad (Figure 5). Her least preferred items were numerous envelopes of hair (with no indication of their origin) and a bottle of 30-year-old mackerel oil.

Christine Williams OBE, the first Hugh Sinclair Chair in Human Nutrition, successfully established nutrition research within the University of Reading under the guidance of Professor Ledingham (University of Oxford) as advisor to the Hugh Sinclair Trust. In 2006, after Professor William's promotion to Dean of Life Sciences and latterly to Pro-Vice Chancellor (2008), Professor lan Rowland was appointed as the second Hugh Sinclair Chair. He steered the nutrition group over the next seven years under the guidance of Professor Alan Jackson (University of Southampton). In 2014, after Professor lan Rowland's retirement, Professor Julie Lovegrove was appointed and is the current Hugh Sinclair Chair. The Nutrition group has expanded from three members in 1995 to the current 
group of 98 (Figure 6). Present academic and academic-related staff include: Professor Parveen Yaqoob, Professor Jeremy Spencer, Dr Orla Kennedy, Dr Gunter Kuhnle, Dr Carole Wagstaff, Dr Danny Commane, Dr Vimal Karani and Dr Kim Jackson. Past academic members include: Dr Ann Walker, Professor Mike Gordon, Professor Anne-Marie Minihane, Professor Gerald Rimbach, Dr Louise Bourne and Dr George Grimble. The current group also consists of 18 postdoctoral research fellows, 55 PhD students, 2 research nurses and 13 technicians and administration staff. In addition to our research expertise, we provide three Association for Nutrition (AfN) accredited degree courses (BSC Nutrition and Food Science, BSc Nutrition and Consumer Sciences and MSc Nutrition and Food Science), with the aims of establishing 'Nutrition' as a professional title and creating the next generation of leaders in nutritional science.

\section{Research highlights from the Hugh Sinclair Unit of Human Nutrition}

Diet-related chronic diseases are estimated to accounts for $90 \%$ of all NHS spend (DEFRA 2014) and have a major impact on morbidity and quality of life. The research undertaken within the HSUHN aims to improve population health by increasing quality of life and preventing chronic diseases, through increasing exposure to key nutrients and giving effective evidence based dietary advice. We continue to develop new and robust strategies of assessing diet and its impact on disease prevention. This will help to determine mechanisms underpinning the influence of food and nutrition on health and develop optimum strategies for disease prevention. We have broadened our approach to exploit emerging cutting edge technologies such as nutrigenomics, nutrigenetics and metabolomics, and applied new imaging techniques including functional magnetic resonance imaging and dual energy $\mathrm{x}$-ray absorptiometry to address these questions. Cross-disciplinary collaborations are a key strength of the group with successful internal partnerships between members of the HSUHN with other groups within the University (Food and Microbial Science, Psychology, Agriculture Policy and Development, Mathematics, Statistics, Biological Sciences, System Engineering, Plant Sciences), the University's Centres of Excellence [Institute for Cardiovascular and Metabolic Research (ICMR), Centre for Integrative Neuroscience and Neurodynamics (CINN) and Centre for Food Secuity (CFS)] and numerous national and international (US, Europe, Arica and Asia) partnerships. Research funding has been awarded from a variety of sources including Research Councils (e.g. Medical Research Council, Biotechnology and Biological Sciences Research Council, European Union), charities (e.g. Wellcome Trust Foundation, British Heart Foundation, Diabetes UK) and industry. Current research within the HSUHN is diverse and key research findings from the past 20 years in the 
areas of 'diet and cardiometabolic health'; 'nutrition, brain and cognition'; 'diet, immunity and cancer'; 'public health nutrition' and 'crops and sustainability' are described below.

\section{Diet and cardiometabolic health}

Dietary fat guidelines are a key strategy for CVD risk reduction and have been central to the work of the HSUHN. Lowering saturated fatty acid (SFA) intake to $\leq 10 \%$ of total energy has been one of the main UK strategies, predominantly due to the strong positive relationship between SFA intake and serum low density lipoprotein-cholesterol (LDL-C), an established risk factor for CVD. However, clear guidance on the optimum replacement for dietary SFA is unclear. A traditional Mediterranean dietary pattern has often been associated with low CVD mortality and one component of these diets is the type of fat consumed by these populations, which is low in SFA and high in monounsaturated fatty acids (MUFA). Early studies by the group revealed that high MUFA, compared with high SFA, diets significantly reduced fasted total and LDL-C concentrations, (Roche et al. 1998) and decreased the expression of adhesion molecule 1 in peripheral blood mononuclear cells, which has implications for inflammatory diseases including CVD (Yaqoob et al. 1998). In addition, cell studies revealed that SFA impacted on the cell morphology, lipid and apoB secretory capacity of intestinal caco-2 cells (Bateman et al. 2007).

We have been instrumental in two of the largest studies to address the question of whether the quantity and quality of dietary fats had a differential effect on CVD risk factors in those at increased risk of CVD and metabolic syndrome: the 5-centre, Reading, Imperial, Surrey, Cambridge and Kings (RISCK) study ( $\mathrm{n}=548)$ (Jebb et al. 2010) and the 8-centre pan-European Lipgene study $(\mathrm{n}=417)$ (Tierney et al. 2011). Using validated dietary exchange models to manipulate dietary fats and carbohydrates without impacting on other components of the habitual diet is one of the key strengths of this group (Nydahl et al. 2003; Moore et al. 2009; Shaw et al. 2009; Lockyer et al. 2012; Weech et al. 2014). Successful application of these dietary interventions demonstrated that substitution of dietary SFA with either MUFA or complex carbohydrates reduced LDL-C, but replacement by MUFA also decreased the clinically relevant total:HDL-C ratio (Jebb et al. 2010). These data added considerable weight to the evidence base for the benefit of SFA replacement with MUFA over carbohydrates in CVD prevention. However there was marked individual variation in response to the dietary interventions associated with genetic polymorphisms (Alsaleh et al. 2011; Garcia-Rios et al. 2011), which may reflect limitations in the efficacy of population wide dietary recommendations and potential benefit of personalised nutrition (Fallaize et al. 2013), a prime interest of the group. Collaboration with large prospective cohort studies has also allowed us to 
determine whether habitual dietary fat intake predicts subsequent disease risk outcomes over a 20year period. In the Caerphilly Prospective cohort study, dietary SFA intake was associated with higher vascular stiffness (measured by pulse wave velocity) compared with high PUFA intake (Livingstone et al. 2013). In support of these data, we have recently reported that $8 \%$ SFA replacement with both $n$ 6 PUFA and MUFA has beneficial effects on multiple lipid risk factors, with replacement of MUFA also associated with a reduction in night time blood pressure and an endothelial function risk marker in the Dietary Intervention and VAScular function (DIVAS) study (Vafeiadou et al. 2015). These data collectively support the efficacy of current dietary fat guidelines to replace SFA with unsaturated fats as a strategy for CVD prevention.

Postprandial (fed) lipid responses are a major research focus of members of the HSUHN. Early studies demonstrated the differential effects of dietary fats on postprandial lipaemia (Zampelas et al. 1994; Murphy et al. 1995), with development of a specific novel assay to quantify apolipoprotein (apo) B-48 [an apoprotein uniquely associated with chylomicrons (CM) and their remnants] enabling pathways of exogenous (intestinally derived) and endogenous (liver derived) triacylglycerol (TAG)rich lipoprotein (TRL) metabolism to be distinguished (Lovegrove et al. 1996). Application of this assay revealed its importance in determining the impact of meal fatty acids on the particle composition and metabolism of intestinally derived TRL (Lovegrove et al. 1999), and cellular mechanisms by which TRLs influence hepatic lipid and endothelial cell metabolism (Williams et al. 2004; Jackson et al. 2006). Collation of the postprandial studies conducted in the HSUHN led to the creation of the Dietary Studies: Reading Unilever Postprandial trials (DISRUPT) database (Jackson et al. 2010), which has greatly expanded current knowledge on the inter-individual variability in postprandial lipid and glucose responses. This comprehensive database, the largest and most detailed of its kind in 2010, includes a novel sequential meal dataset that has provided both confirmatory and novel insights into the physiological (age, gender, menopausal status and the metabolic syndrome) (Jackson et al. 2010; 2012) and genetic (APOA5 haplotype, APOE, APOB and LEPR polymorphisms) determinants (Olano-Martinet et al. 2008; Carvahlo-Wells et al. 2010; Jackson et al. 2012; Vimaleswaran et al. 2015) of the postprandial response.

Evidence now indicates that transient changes in postprandial vascular function could have implications for long-term vascular health (Vafeiadou et al. 2012). Following on from the legacy of Hugh Sinclair, more recent studies have revealed some novel insights into the mechanisms underlying the positive benefits of fish oil-rich meals on postprandial vascular reactivity (Armah et al. 2008; Thompson et al. 2012) and arterial stiffness (Chong et al. 2010). Complementary in vitro studies indicated that, acutely, EPA and DHA may lead to improvements in vascular function by 
increasing the bioavailability of nitric oxide (a potent vasodilator produced by the endothelium) and by reducing the oxidative status of the vascular wall (Armah et al. 2008). Furthermore, both gender and a single nucleotide polymorphism in the eNOS gene (Glu298Asp) (Thompson et al. 2012) have been identified as important determinants of the magnitude of the increase in flow mediated dilatation after addition of fish oil to a SFA-rich test drink. These data may be important in identifying population subgroups with greater responsiveness to the beneficial effects of LC n-3 PUFA.

\section{Nutrition, brain and cognition}

The number of people with dementia in the population is predicted to reach approximately 1.1 million by 2025, a $40 \%$ increase in 12 years (Alzheimer's Society, 2015) and highlights the urgent need for a more comprehensive understanding of how different aspects of lifestyle (in particular diet and exercise) may affect neural function and consequent cognitive performance throughout the life course. In this regard, flavonoids, polyphenols and other secondary metabolites of plants, found in a variety of fruits, vegetables, grains and derived beverages, have been identified as a group of promising bioactive compounds capable of influencing different aspects of brain function. These include increased cerebrovascular blood flow and synaptic plasticity, which result in improvements in memory and neurocognitive performance in humans and other mammalian species (RodriguezMateos et al. 2014a).

Data from human intervention trials demonstrate that consumption of flavonoid-rich foods is associated with cognitive benefits (for a review see Macready et al. 2009). The mechanisms by which flavonoids exert these actions on cognitive performance are currently being investigated, with evidence from our research on long-term flavonoid supplementation in animals suggesting that synaptic plasticity is modulated through activation of neuronal receptors, signaling proteins and gene expression (Rendeiro et al. 2012; 2013). However, the ability of flavonoids to directly modulate brain plasticity may be dependent, to some extent, on their accessibility to the brain, which is likely to vary based on the structural characteristics of in vivo flavonoid metabolites (Youdim et al. 2003). As such, whether flavonoid induced cognitive effects are mediated directly within the brain or involve other mechanisms triggered from the periphery remains unclear and are the topic of current investigation in the HSUHN. With respect to the latter, there is substantial evidence in support of the beneficial effects of flavonoids on peripheral vascular health (Hooper et al. 2012). Notably, we have shown that anthocyanins (Rodriguez-Mateos et al. 2014b), and also flavanols (Schroeter et al. 2006), are capable of promoting clinically significant improvements in endothelial-dependent peripheral 
vascular function (measured using flow mediated dilatation of the brachial artery) and blood pressure. Such effects seem to be mediated by the actions of absorbed flavonoid metabolites on artery nitric oxide bioavailability, through their potential to either activate the eNOS gene (Schroeter et al. 2006) and/or inhibit nicotinamide adenine dinucleotide phosphate oxidase (Rodriguez-Mateos et al. 2013) in the endothelium. The extent to which such benefits in vascular responses in peripheral arteries might be translatable to benefits in cerebral arteries and improved vascularisation of the brain is currently being explored, with some encouraging clinical data showing increases in cerebral blood flow (CBF) matching closely the timing of peripheral responses following the intake of flavanols intake (Lamport et al. 2015). As such, it has been hypothesised that improvements in human cognitive function observed following flavonoid intake might be partly mediated by increases in CBF (Brickman et al. 2014). The ability of flavonoids to facilitate CBF is significant given that data indicate that accentuated declines in brain blood perfusion occur in parallel to aging and other neurological disorders implicated in the development of various dementias (Spencer 2010). These data highlight the potential for flavonoids to help reduce cognitive decline.

\section{Diet, immunity and cancer}

Undernutrition impairs the immune system, suppressing immune functions that are fundamental to host protection against pathogenic organisms. However, while the effects of malnutrition on immunity are well recognised, the potential for immunomodulatory properties of a wide range of dietary components, some of which are non-nutrients, is subject to significant research activity. Fatty acids have diverse roles in all cells, acting as sources of energy, structural molecules and precursors for the synthesis of eicosanoids. Supplementation of the diet with fish oil-derived LC n-3 PUFA alters the composition of immune cell membranes and the production of immune and inflammatory mediators (Yaqoob 2003). In pregnant women, consumption of salmon from week 20 of pregnancy until birth resulted in modulation of the fatty acid and immune composition of breastmilk, but this did not appear to have any impact on infant health (Urwin et al. 2012). Moreover, in both cases, the physiological relevance is not clear. There is some evidence for antiinflammatory effects of LC n-3 PUFA, which may contribute to lowering of CVD risk and beneficial effects on vascular function (Calder \& Yaqoob 2012). Recent work exploring cellular mechanisms for the effects of LC n-3 PUFA on vascular function has demonstrated that they lower circulating levels of endothelial microparticles, thought to be produced as a result of damage to the endothelium, and 
increase numbers of endothelial progenitor cells, which are associated with vascular repair and angiogenesis (Wu et al. 2014).

A second area of current activity is investigation of the immunomodulatory effects of probiotics. Studies have consistently demonstrated enhancement of innate immunity, particularly natural killer cell activity, by probiotics (Dong et al. 2012, 2013). The effect appears to be influenced by ageing, since probiotics enhance natural killer cell activity and production of key cytokines to a much greater degree in cells from young subjects compared with those from older subjects (You and Yaqoob 2012; You et al. 2014). Comparative studies of different strains suggest that immunomodulatory potential is strain-dependent and that the effects of most strains are influenced by ageing (You and Yaqoob 2012; You et al. 2014). There is current interest in testing the ability of probiotics to modulate the immune response to vaccination (Maidens et al. 2013).

It is estimated that over $25 \%$ of all cancers are attributable to dietary factors (WCRF, 2009) and we have explored, amongst other areas, the role of diet and gut microbiota in colorectal cancer. The study of cancer causation is somewhat constrained by the relatively poor availability of suitable endpoints for human intervention trials. As a result, much of what we understand about diet and lifestyle in cancer is derived from large cohort studies, which cannot prove causality or elucidate mechanisms. Biomarkers of risk that are amenable to diet manipulations in randomised controlled trials are therefore required. Research by members of the HSUHN has focused on developing and utilising the biological activities of faecal water as a surrogate end-point for use in intervention studies. Applying faecal water, isolated from volunteers, to cells in culture induces a gradient of inter-individual effects on measures of DNA damage, epithelial integrity and differentiation, cell turnover and cell proliferation (Pearson, Gill \& Rowland 2009). The strengths of this approach are that faecal water can be collected non-invasively; its isolates are directly indicative of toxic exposures, at least within the recto-sigmoid colon; and biological activity of faecal water samples has been shown to be modifiable by dietary intervention with exposures related to the cancer process (Fässler et al. 2007). This biomarker is now routinely used in dietary interventions and crosssectional studies to evaluate foods and microbial exposures which may be implicated in the cancer process (Eid et al. 2014). A current strand of research also seeks to explore the metabolomic profile of faecal water samples and/or urinary metabolites to further elucidate cancer-related exposures within the colonic environment and potentially negating the need for semi-quantitative biological measures of risk.

\section{Public Health Nutrition}


The accurate assessment of dietary intake, both in large observational studies and in small intervention trials, is important for reliable outcomes to be obtained. However, dietary assessment still relies largely on self-reporting, which is prone to systematic bias affected by factors such as age, sex, social desirability and approval (Herbert et al. 1995; Herbert et al. 1997). Self-reporting via food frequency questionnaires (FFQ) is known to result in over-reporting of commonly perceived 'healthy' foods (Bingham 1997) whereas obese people are known to underreport total energy, protein (Lissner et al. 2007) and sugars (Bingham et al. 2007) intake. Prospective methods, such as food diaries, can affect dietary intake and thereby introduce bias. The resulting measurement error can attenuate observed associations and thereby make it difficult to identify actual links between diet, health and disease. For this reason, research into new and more reliable methods of dietary assessment, such as automated 24 hour-recall systems or smart phone based applications, are very important and a recent interest of the HSUHN. An alternative to self-reporting are objective markers of intake, so-called nutritional biomarkers, which can be used to overcome these limitations and provide an alternative, more objective, method of dietary assessment especially when combined with other information.

Nutritional biomarkers can be used for specific compounds, compound classes or dietary patterns, although they are most commonly used to identify specific compounds. This is particularly important for foods that are often underreported, such as those commonly considered to be 'unhealthy'. The effect of sugars intake on bodyweight has been discussed extensively and controversially in recent years. Many observational studies have failed to show positive associations between sugars intake and body weight, and this has resulted not only in conflicting advice and guidance (EFSA 2010) but has also been used to promote sugars consumption by the German Sugar Industry forum. However, the discrepancy between self-reported and actual sugars intake becomes obvious when using an objective biomarker, in particular in overweight or obese people and sugars intake - measured objectively - was associated with the risk of being overweight or obese (Kuhnle et al. 2015).

A different application of nutritional biomarkers is the assessment of more complex dietary patterns and interactions between dietary and metabolic factors. Stable carbon and nitrogen isotope ratios have been used very successfully to assess dietary patterns and food webs in ecological, anthropological and archaeological research. In recent years, use of stable isotopes have slowly found their way into nutritional research and in particular nutritional epidemiology. They can provide information on the main macronutrient sources and distinguish between animal and plant based, as well as terrestrial and marine, food sources (Kuhnle et al. 2013). Furthermore, they can be used to investigate interactions between different foods and estimate disease risk (Patel et al. 2014). 


\section{Crops and sustainability}

Over the 20-year history of the HSUHN nutritionists and the public alike have become far more aware of the importance of consuming a range of fruit and vegetables within the daily diet. Plantbased food should provide the bulk of daily food intake. Combinable crops provide fibre, carbohydrate, vegetable protein, phytochemicals such as ferulic acid, and micronutrients such as selenium, depending on which variety of crop is grown and the composition of the soil in which it is growing. However, much of the public interest around healthy diets, and the research interests of researchers in the HSUHN, is focused on the composition and consumption of fruit and vegetables.

Our research focus is also on the quality of the crop itself. Our philosophy is to take a multi-targeted approach to increase the amount of phytonutrients consumed in the daily human diet as most people fail to reach the 'five-a-day' recommendations with the average intake of approximately four portions of fruit or vegetables per day (Bates et al. 2014). We are therefore working to increase the nutritional density of crops at the point of harvest, reduce losses in nutrients during the post-harvest supply chain, and improve the flavour of fruit and vegetables. The nutritional characteristics of a crop are a product of its genetics and the environment in which it is produced; hence plant breeding and agronomy are equally important. Manipulating plant architecture through agronomic methods, such as planting density, can drastically change the yield (Bennett et al. 2013) and manipulation of the environment, such as by changing light intensity, can significantly alter the concentration of phytochemicals in the crop (Jin et al. 2009). Post-harvest changes can be extremely significant in terms of deterioration of physiological and nutritional aspects of the crop, particularly in vulnerable crops such as baby leaf salads (Wagstaff et al. 2007). Changes in volatiles caused by crop ageing and the packaging environment also occur, usually to the detriment of quality (Bell et al. 2015). As with all phytonutrients, the plant produces the compounds for reasons other than human nutrition, for example as a defense against herbivory, and it is important to understand the complexity of pathways within the plant before we start to manipulate them for nutritional benefit (Chadwick et al. 2013). Much of the work undertaken is focused on crops from the Brassicaceae family due to their rich content of glucosinolates and isothiocyanates which confer benefits such as lowering the risk of certain cancers (Richman et al. 2012). An integrative study combining plant genetics and metabolomics has identified targets for breeding programs of Brassicaceous salad crops that potentially confer health benefits without compromising flavour (Bell and Wagstaff 2014; Bell et al. 2015). 
Food security is now a term in widespread use and which refers to the availability of sufficient, safe and nutritious food for all people at all times This is set alongside a need for sustainability of the global food system in terms of the environment, economics and people involved. In the HSUHN we address both the intensification of production (Bennett et al. 2011; 2012) and the reduction of waste throughout the food system (unpublished commercial work). In order to sustain a growing population within the UK, and to maintain a buoyant export market that can provide food for areas of the world with a less favorable growing environment, we need to continue to strive to produce high quality food and animal feed on limited land, which is nutritious, flavoursome, conveniently available and with a reliable shelf life.

\section{Future of Nutrition}

Nutrition plays an essential role in health, wellbeing and the risk of chronic diseases, with optimal dietary choices being of paramount importance. The sustained provision of adequate nutrition is a key global challenge that has assumed even greater relevance to human health because of the exponential growth and increasing age of the world's population. To address this challenge, we must gain a better understanding of the mechanisms that underpin the effects of food and nutrition on long-term health. This endeavour has created exciting opportunities in nutritional research within HSUHN, which is well equipped (with state of the art equipment, clinical facilities and nutrition experts) to provide the scientific evidence to support dietary guidelines for chronic disease prevention and provision of nutritionally optimised foods. Our research focus is diverse, multifaceted, cutting edge and spans farm to fork and beyond.. Our vision is to expand the physical infrastructure, research resources, staff and students in the HSUHN. We will continue to develop new and innovative technologies, and to forge multidisciplinary collaborations around the world to address the pressing nutritional issues. The future will be an exciting time to be in nutrition research. If Hugh Sinclair were alive today, we could assure him that his legacy and the research he made possible in the HSUHN, will continue to thrive and impact on human nutrition for many years to come.

\section{Acknowledgement}

Thanks go to Dr Rosalind Fallaize and Professor Bruce Griffin for providing valuable comments on the manuscript. 


\section{References}

Alzheimer's Society (https://www.alzheimers.org.uk/statistics)

Armah CK, Jackson KG, James L, Doman I, Cheghani F and Minihane AM (2008). Fish oil fatty acids improve postprandial vascular reactivity in healthy men. Clinical Science 114, 679-686.

Bang HO, Dyerberg J, Sinclair HM. (1980). The composition of the Eskimo food in north western Greenland. Am J Clin Nutr. 1933(12):2657-61.

Bateman, P.A.,. Jackson, K.G.,. Maitin, V.,. Yaqoob, P. and Williams, C.A. (2007) Differences in cell morphology, lipid and apo B secretory capacity in caco-2 cells following long term treatment with saturated and monounsaturated fatty acids. Biochimica Et Biophysica Acta-Molecular and Cell Biology of Lipids, 1771 (4). pp. 475-485

Bates B, Lennox A, Prentice A et al. (2014). National Diet and Nutrition Survey. Results from Years 1, 2, 3 and 4 (combined) of the Rolling Programme (2008/2009 2011/2012). Department of Health: London. Available at: https://www.gov.uk/government/uploads/system/uploads/attachment data/file/310 995/NDNS Y1 to 4 UK report.pdf (accessed ????)

Bell, L, Spadafora, N.D.,. Müller, C.T.,. Wagstaff, C and Rogers, H.J. (2015). Use of TD-GC-TOF-MS to assess volatile composition during post-harvest storage in seven accessions of rocket salad (Eruca sativa). Food Chemistry. In press.

Bell, L.,. M.J. Oruna-Concha and Wagstaff, C. (2015). Identification and quantification of glucosinolate and flavonol compounds in rocket salad (Eruca sativa, Eruca vesicaria and Diplotaxis tenuifolia) by LC-MS: highlighting the potential for improving nutritional value of rocket crops. Food Chemistry 172: 852-861

Bell, L. and Wagstaff, C. (2014).. Glucosinolates, myrosinase hydrolysis products and flavonols found in rocket (Eruca sativa and Diplotaxis tenuifolia). Journal of Agricultural Food Chemistry. 62: 44814492.

Bennett, E.J.,. Gawthrop, F.,. Yao, C.,. Boniface, C.,. Ishihara, H.,. Roberts, J.A. and Wagstaff, C. (2013). Effects of planting density and nitrogen application on seed yield and other morphological traits of the leafy vegetable kale (Brassica oleracea). Aspects of Applied Biology 119: 201-216.

Bennett, E.,. Roberts, J.A. and Wagstaff, C. (2012). Manipulating resource allocation in plants. Journal of Experimental Botany. 63: 3391-3400.

Bennett, E.,. Roberts, J.A. and Wagstaff, C. (2011). The role of the pod in seed development: strategies for manipulating yield. New Phytologist Tansley Review. 190: 838-853.

Bingham SA (1997) Dietary assessments in the European prospective study of diet and cancer (EPIC). Eur J Cancer Prev 6, 118-124.

Bingham S, Luben R, Welch A et al. (2007) Epidemiologic assessment of sugars consumption using biomarkers: comparisons of obese and nonobese individuals in the European prospective investigation of cancer Norfolk. Cancer Epidemiol Biomarkers Prev 16, 1651-1654.

Brickman AM, et al. (2014) Enhancing dentate gyrus function with dietary flavanols improves cognition in older adults. Nature neuroscience 17(12):1798-1803. 
Calder, P.C. and Yaqoob, P. (2012) Marine omega-3 fatty acids and coronary heart disease. Current Opinion in Cardiology 27, 412-419.

Carvalho-Wells AL, Jackson KG, Gill R, Olano-Martin E, Lovegrove JA, Williams CM and Minihane AM (2010). Interactions between age and apoE genotype on fasting and postprandial triglyceride levels. Atherosclerosis 212, 481-487.

Chadwick, M.,. Trewin, H.,. Gawthrop, F. and Wagstaff, C. (2013). Sesquiterpenoid Lactones: Benefits to Plants and People. International Journal of Molecular Science. 14: 12780-12805.

DDFRA. (2014) Food Statistics Pocketbook

Dong, H.,. Rowland, I. and Yaqoob, P. (2012) Comparative effects of six probiotics on immune function in vitro. British Journal of Nutrition 108, 459-470.

Dong, H.,. Thomas, L.,. Rowland, I. and Yaqoob, P. (2013) Immunomodulatory effects of a probiotic drink containing Lactobacillus casei Shirota in healthy older volunteers. Eur. J Nutr.,. 52, 1853-1863.

Eid N, Enani S, Walton G, Corona G, Costabile A, Gibson G, Rowland I, Spencer JP. (2014). The impact of date palm fruits and their component polyphenols, on gut microbial ecology, bacterial metabolites and colon cancer cell proliferation. J Nutr Sci. 8;3:e46.

Ewin, J. and Horrobin, D.F. (2001) Fine Wine and Fish Oils: The Life of Hugh Sinclair. Oxford University Press, pg. xiii

Fallaize R, Macready AL, Butler LT, Ellis JA, Lovegrove JA. (2013). An insight into the public acceptance of nutrigenomic-based personalised nutrition. Nutr Res Rev 26;39-48.

Fallaize R, Lovegrove JA. (2013) Professor Hugh Macdonald Sinclair - one of the pioneering nutritionists of our day. Network Health Dietitians Magazine, 87: 24-25.

Fässler C1, Gill Cl, Arrigoni E, Rowland I, Amadò R. (2007). Fermentation of resistant starches: influence of in vitro models on colon carcinogenesis. Nutr Cancer. 58(1):85-92.

Hebert JR, Clemow L, Pbert L et al. (1995) Social Desirability Bias in Dietary Self-Report May Compromise the Validity of Dietary Intake Measures. Int J Epidemiol 24, 389-398.

Hebert JR, Ma Y, Clemow L et al. (1997) Gender Differences in Social Desirability and Social Approval Bias in Dietary Self-report. Am J Epidemiol 146, 1046-1055.

Hooper L, et al. (2012) Effects of chocolate, cocoa, and flavan-3-ols on cardiovascular health: a systematic review and meta-analysis of randomized trials. The American journal of clinical nutrition 95(3):740-751.

Jackson KG, Maitin V, Leake DS, Yaqoob P and Williams CM (2006). Saturated fat induced changes in $\mathrm{S}_{\mathrm{f}}$ 60-400 particle composition reduces uptake of LDL by HepG2 cells. Journal of Lipid Research 47, 393-403.

Jackson KG, Clarke DT, Murray P, Lovegrove JA, O'Malley B, Minihane AM and Williams CM (2010). Introduction to the DISRUPT postprandial database: subjects, studies and methodologies. Genes and Nutrition 5, 39-48. 
Jackson KG, Abraham EC, Smith AM, Murray P, O'Malley B, Williams CM and Minihane AM (2010). Impact of age and menopausal status on the postprandial triacylglycerol response in healthy women. Atherosclerosis 208, 246-252.

Jackson KG, Delgado-Lista J, Gill R, Lovegrove JA, Williams CM, López-Miranda J, Minihane AM (2012). The leptin receptor GIn223Arg polymorphism (rs1137101) mediates the postprandial lipaemic response, but only in males. Atherosclerosis 225, 135-141.

Jackson KG, Walden CM, Murray P, Smith AM, Lovegrove JA, Minihane AM and Williams CM (2012). A sequential two meal challenge reveals abnormalities in postprandial TAG but not glucose in men with increasing numbers of metabolic syndrome components. Atherosclerosis 220, 237-243.

Jebb S, Lovegrove JA, Griffin B, Frost G, Moore C, Bluck MDLK, Williams CM, Sanders TAB on behalf of the RISCK STUDY GROUP.(2010). Impact of changing the amount and type of fat and carbohydrate on insulin sensitivity and cardiovascular risk: the RISCK trial. American Journal of Clinical Nutrition 92:748-58.

Jin, J.,. Koroleva, O.,. Gibson, T.,. Swanston, J.,. Magan, J.,. Zhang, Y.,. Rowland, I.R. and Wagstaff, C. (2009). Analysis of Phytochemical Composition and Chemoprotective Capacity of Rocket (Eruca sativa and Diplotaxis tenuifolia) Leafy Salad Following Cultivation in Different Environments. Journal of Agricultural Food Chemistry. 57: 5227-5234.

Kuhnle GG, Tasevska N, Lentjes MA, Griffin JL, Sims MA, Richardson L, Aspinall SM, Mulligan AA, Luben RN, Khaw KT. (2015) Association between sucrose intake and risk of overweight and obesity in a prospective sub-cohort of the European Prospective Investigation into Cancer in Norfolk (EPICNorfolk). Public Health Nutrition, epub

Kuhnle GG, Joosen AM, Kneale CJ, O'Connell TC. (2013) Carbon and nitrogen isotopic ratios of urine and faeces as novel nutritional biomarkers of meat and fish intake. Eur J Nutr 52(1):389-395

Lamport DJ, et al. (2015) The effect of flavanol-rich cocoa on cerebral perfusion in healthy older adults during conscious resting state: a placebo controlled, crossover, acute trial. Psychopharmacology.

Lissner L, Troiano RP, Midthune D et al. (2007) OPEN about obesity: recovery biomarkers, dietary reporting errors and BMI. Int J Obes (Lond) 31, 956-961.

Lloyd, B.B. (2004) 'Sinclair, Hugh Macdonald (1910-1990)', rev. Oxford Dictionary of National Biography, Oxford University Press

Lockyer S, Tzanetou M, Carvalho-Wells AL, Jackson KG, Minihane AM, Lovegrove JA. (2012). SATgen dietary model to implement diets of differing fat composition in prospectively genotyped groups (apoE) using commercially available foods. British Journal of Nutrition. 108;1705-13

Macready AL, et al. (2009) Flavonoids and cognitive function: a review of human randomized controlled trial studies and recommendations for future studies. Genes \& nutrition 4(4):227-242.

Maidens, C.,. Childs, C.E.,. Przemska, A.,. Bin dayel, I. and Yaqoob, P. (2013) Modulation of the vaccine response by concomitant probiotic administration. British Journal of Pharmacology 75, 663670. 
McLean, A. (2002) Fine Wines and Fish Oil: the life of Hugh Macdonald Sinclair. Journal of the Royal Society of Medicine, 96: 263-264

Moore C, Gitau R, Goff L, Lewis FJ, Griffin MD, Chatfield MD, Jebb S, Frost G, Griffin BA, Sanders T, Lovegrove JA. (2009). On behalf of the RISCK Study Group. Manipulation of the quality and quantity of fat and carbohydrate consumed by free-living individuals using a food exchange model was successful. Journal Nutrition 139:1534-1540.

Murphy MC, Isherwood SG, Sethi S, Gould BJ, Wright JW, Knapper JA and Williams CM (1995) Postprandial lipid and hormone responses to meals of varying fat contents: modulatory role of lipoprotein lipase? European Journal of Nutrition 49, 578-588.

Department of Health National Diet and Nutrition Survey: results from Years 1 to 4 (combined) of the rolling programme for 2008 and 2009 to 2011 and 2012. 2014. Available from: https://www.gov.uk/government/publications/national-diet-and-nutrition-survey-results-fromyears-1-to-4-combined-of-the-rolling-programme-for-2008-and-2009-to-2011-and-2012 (cited 14 May 2014).

Nydahl, M.C.,. Smith, R.D.,. Kelly, C.N.M.,. Fielding, B.A. and Williams, C.M. (2003) Achievement of dietary fatty acid intakes in long-term controlled intervention studies: approach and methodology. Public Health Nutrition, 6 (1). pp. 31-40

Olano-Martin E, Abraham EC, Gill-Garrison R, Valdes AM, Grimaldi K, Tang F, Jackson KG, Williams $C M$ and Minihane AM (2008). Influence of ApoA5 gene variants on postprandial triglyceride metabolism: Impact of gender. Journal of Lipid Research 49, 945-953.

Patel PS, Cooper AJ, O'Connell TC, Kuhnle GG, Kneale CK, Mulligan AM, Luben RN, Brage S, Khaw KT, Wareham NJ, Forouhi NG. (2014) Serum carbon and nitrogen stable isotopes as potential biomarkers of dietary intake and their relation with incident type 2 diabetes: the EPIC-Norfolk study. AJCN 100(2)708-718

Pearson JR1, Gill Cl, Rowland IR. (2009). Diet, fecal water, and colon cancer--development of a biomarker. Nutr Rev. 67(9):509-26.

Rendeiro C, et al. (2012) Blueberry supplementation induces spatial memory improvements and region-specific regulation of hippocampal BDNF mRNA expression in young rats. Psychopharmacology 223(3):319-330.

Rendeiro C, et al. (2013) Dietary levels of pure flavonoids improve spatial memory performance and increase hippocampal brain-derived neurotrophic factor. PloS one 8(5):e63535.

Richman EL, Carroll PR, Chan JM (2012). Vegetable and fruit intake after diagnosis and risk of prostate cancer progression. International Journal of Cancer 131: 201-210.

Roche HM1, Zampelas A, Knapper JM, Webb D, Brooks C, Jackson KG, Wright JW, Gould BJ, Kafatos A, Gibney MJ, Williams CM. (1998). Effect of long-term olive oil dietary intervention on postprandial triacylglycerol and factor VII metabolism. Am J Clin Nutr. 8(3):552-60.

Rodriguez-Mateos A, et al. (2014a) Bioavailability, bioactivity and impact on health of dietary flavonoids and related compounds: an update. Archives of toxicology 88(10):1803-1853.

Rodriguez-Mateos A, et al. (2014b) Impact of processing on the bioavailability and vascular effects of blueberry (poly)phenols. Molecular nutrition \& food research 58(10):1952-1961. 
Rodriguez-Mateos A, et al. (2013) Intake and time dependence of blueberry flavonoid-induced improvements in vascular function: a randomized, controlled, double-blind, crossover intervention study with mechanistic insights into biological activity. The American journal of clinical nutrition 98(5):1179-1191.

Scientific Opinion on Dietary Reference Values for carbohydrates and dietary fibre. (2010). EFSA Journal 8:1462-153

Shaw DI, Tierney A, McCarthy S, Uprichard J, Vermunt S, Gulseth H, Drevon C, Blaak E, Saris W, Karlstrom B, Helal O, Defoort C, Gallego R, Siedlecka D, Malczewska-Malec M, Lopez-Miranda J, Roche $\mathrm{H}$, Lovegrove JA. (2009). LIPGENE food exchange model for alteration of dietary fat quantity and quality, in free-living participants with the metabolic syndrome from eight European countries. British Journal Nutrition 101:750-759.

Sinclair, H.M. (1956) Deficiency of essential fatty acids and atherosclerosis, etcetera. Lancet, 270(6919):381-383

Spencer JP (2010) Beyond antioxidants: the cellular and molecular interactions of flavonoids and how these underpin their actions on the brain. The Proceedings of the Nutrition Society 69(2):244260.

Tierney AC, McMonagle J.,. Shaw DI, Gulseth HI, Helal O, Saris WHM, Paniagua JA, GołąbekLeszczyńska I, Defoort C, Williams CM, Karsltröm B, Vessby B, Dembinska-Kiec A, López Miranda J, Blaak E, Drevon CA, Gibney MJ, Lovegrove JA, Roche HM. (2011). Dietary saturated fat modification and risk factors of the metabolic syndrome. Insights from LIPGENE - a randomised European dietary intervention study. International Journal of Obesity 35(6):800-9

Thompson AK, Newens KJ, Jackson KG, Todd SC, Wright J, Williams CM (2012). Glu298Asp polymorphism influences the beneficial effects of fish oil fatty acids on postprandial vascular function. Journal of Lipid Research 53, 2205-2213.

Urwin, H.J.,. Miles, E.A.,. Noakes, P.S.,. Kremmyda, L-S.,. Vlachava, M.,. Diaper, N.D.,. Perez-cano, F.J.,. Godfrey, K.M.,. Calder, P.C. and Yaqoob, P. (2012) Salmon consumption during pregnancy alters fatty acid composition and secretory IgA concentration in human breast milk. Journal of Nutrition 142, 1603-1610.

Vafeiadou K, Weech M, Altowaijri H, Todd S, Yaqoob P, Jackson KG, Lovegrove JA.(2015). Replacement of saturated with unsaturated fats had no impact on vascular function but beneficial effects on lipid biomarkers, E-selectin and blood pressure: results from the randomized, controlled Dietary Intervention and VAScular function (DIVAS) study. Am. J Clin Nutr 101(6); .

Vimaleswaran KS, Minihane AM, Li Y, Gill R, Lovegrove JA, Williams CM, Jackson KG (2015). The $A P O B$ insertion/deletion polymorphism (rs17240441) influences postprandial lipaemia in healthy adults. Nutrition \& Metabolism 12, 7.

Wagstaff, C.,. Clarkson, G.J.J.,. Rothwell, S.D.,. Page, A.,. Taylor, G. and Dixon, M.S. (2007). Characterisation of cell death in bagged baby salad leaves. Postharvest Biology and Technology. 46: 150-159. 
Weech M, Vafeiadou K, Hasaj M, Todd S, Yaqoob P, Jackson KG, Lovegrove JA. (2014). Development of a Food-Exchange Model to Replace Saturated Fat with MUFAs and n-6 PUFAs in Adults at Moderate Cardiovascular Risk. Journal of Nutrition 44(6):846-55

Williams CM, Maitin V and Jackson KG (2004) Triglyceride-rich lipoprotein-gene interaction in endothelial cells. Biochemistry Society Transactions 32, 994-998.

Williams RJ \& Spencer JP (2012) Flavonoids, cognition, and dementia: actions, mechanisms, and potential therapeutic utility for Alzheimer disease. Free Radic Biol Med 52(1):35-45.

World Cancer Research Fund: Diet and Cancer Report (2009).

Wu, S-Y.,. Mayneris-Perxachs, J.,. Lovegrove, J.A.,. Todd, S. and Yaqoob, P. (2014) Fish-oil supplementation alters numbers of circulating endothelial progenitor cells and microparticles independent of eNOS genotype. American Journal of Clinical Nutrition. 100, 1232-1243.

Yaqoob, P. (2003) Fatty acids as gatekeepers of immune cell regulation. Trends in Immunology. 24, 639-645.

Yaqoob, P.,. Knapper, J. A.,. Webb, D. H.,. Williams, C. M.,. Newsholme, E. A. and Calder, P. C. (1998) Effect of olive oil on immune function in middle-aged men. American Journal of Clinical Nutrition, 67 (1). pp. $129-135$

Ye EQ, Chacko SA, Chou EL, Kugizaki M and Liu S. 2012. Greater Whole-Grain Intake Is Associated with Lower Risk of Type 2 Diabetes, Cardiovascular Disease, and Weight Gain. J. Nutr. 142: 13041313.

You, J. and Yaqoob, P. (2012) Evidence of immunomodulatory effects of a novel probiotic, Bifidobacterium longum bv. Infantis CCUG 52486. FEMS Immunology and Medical Microbiology 66, 353-362.

You, J.,. Dong, H.,. Mann, E.R.,. Knight, S.C.,. Yaqoob, P. (2014) Probiotic modulation of dendritic cell function is influenced by ageing. Immunobiology 219, 138-148.

Youdim KA, et al. (2003) Interaction between flavonoids and the blood-brain barrier: in vitro studies. J Neurochem 85(1):180-192.

Zamelas A, Peel AS, Gould BJ, Wright JW, Williams CM (1994) Polyunsaturated fatty acids of the $n-6$ and $n-3$ series: effects on postprandial lipid and apolipoprotein levels in healthy men. European Journal of Nutrition $48,842-8$. 


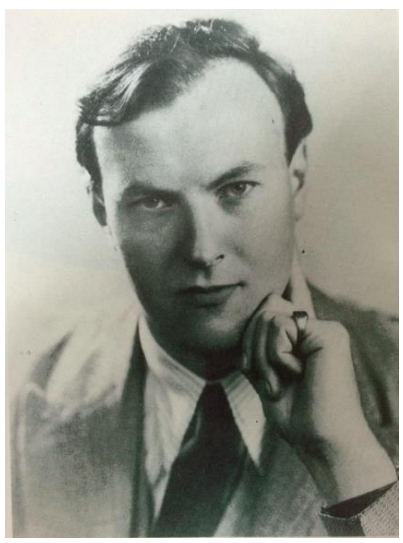

Figure 1. Professor Hugh Macdonald Sinclair.

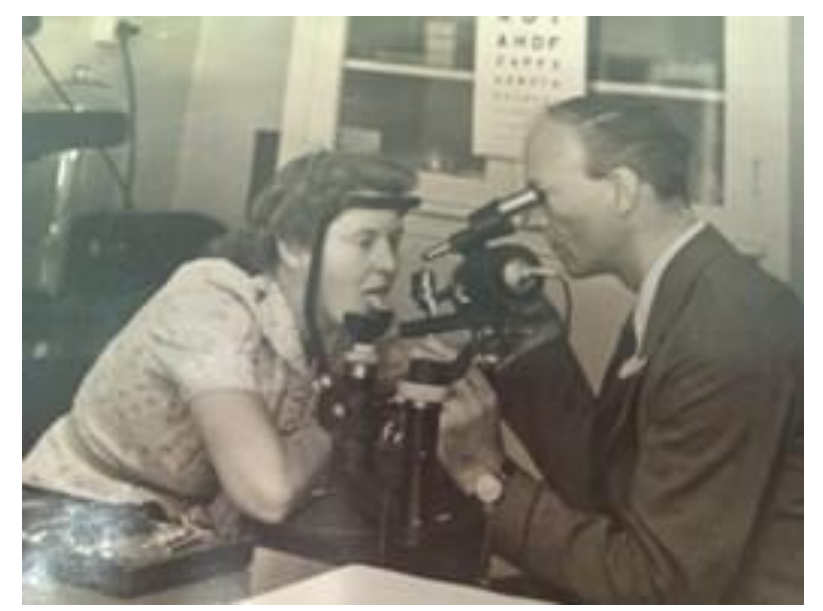

Figure 2. Professor Sinclair performing a physical examination for the Oxford Nutrition Survey. 


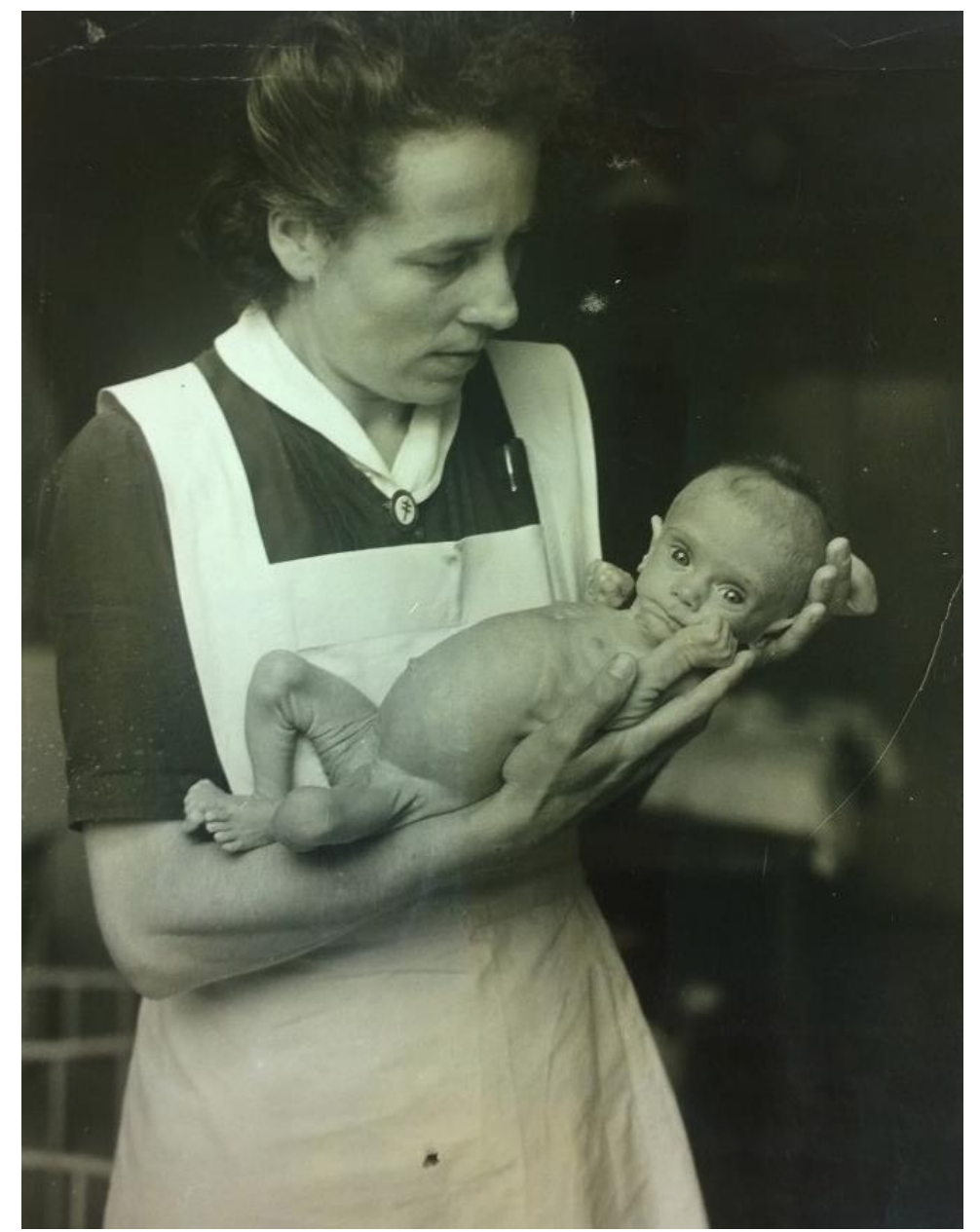

Figure 3. A new born child in The Netherlands days after the blockade was lifted in May 1945. 


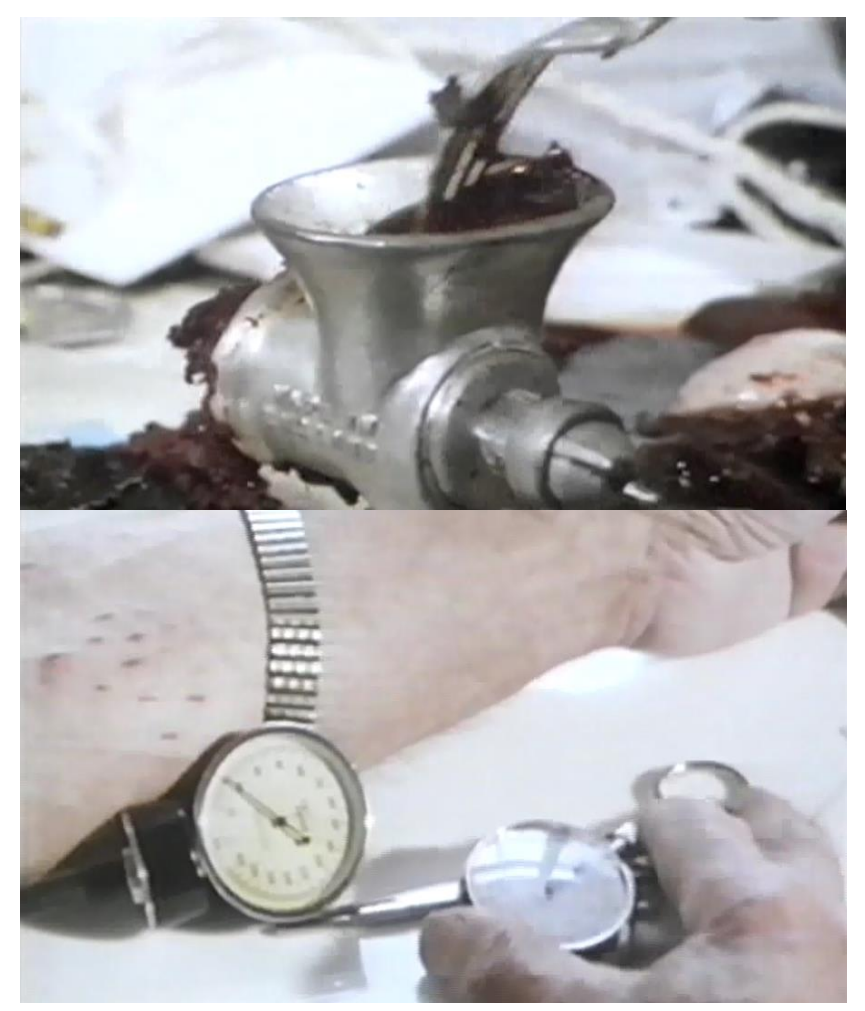

Figure 4A. Mincing whale meat for the 100 day Inuit diet; 4B. Professor Sinclair timing his blood clotting time after cutting his arm. 


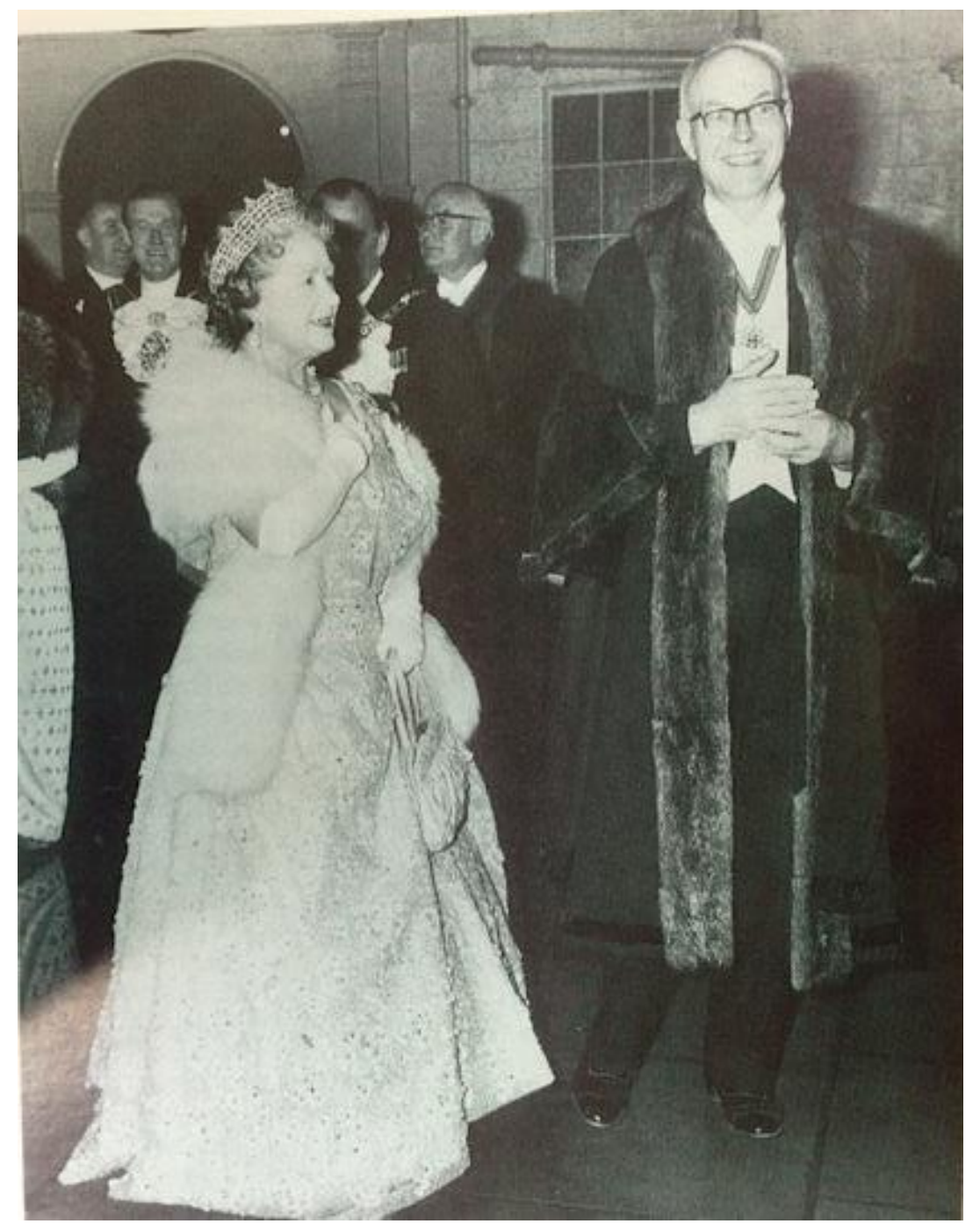

Figure 5. Professor Hugh Sinclair meeting the Queen mother. 
Figure 6. Some staff and student members of the Hugh Sinclair Unit of Human Nutrition, September 2015.

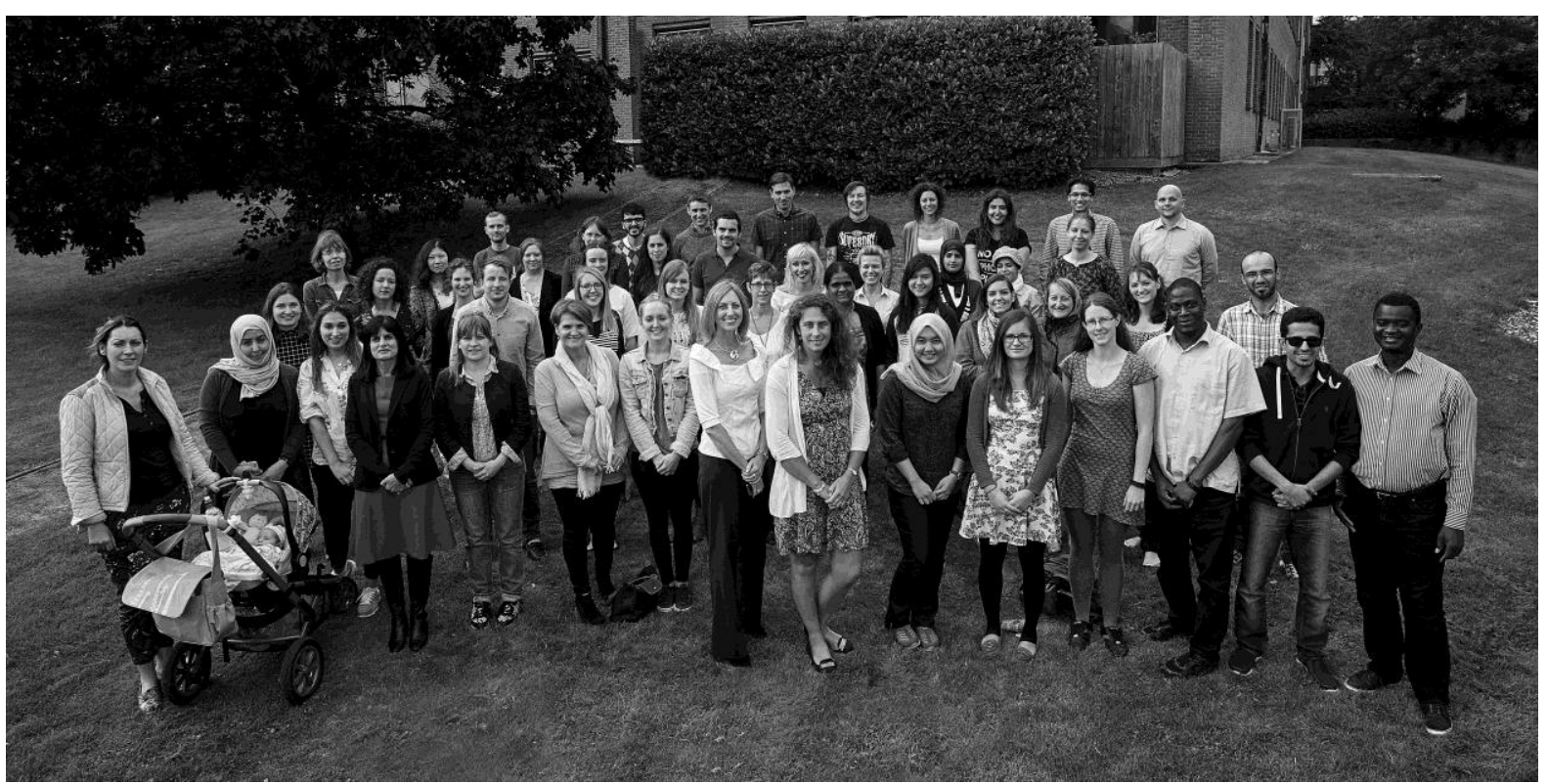

